Florida International University FIU Digital Commons

FIU Electronic Theses and Dissertations

University Graduate School

4-22-1991

\title{
Age differences in functional performance : deficits or artifacts?
}

Anne E. Dickerson

Florida International University

DOI: $10.25148 /$ etd.FI14062282

Follow this and additional works at: https://digitalcommons.fiu.edu/etd

Part of the Psychology Commons

\section{Recommended Citation}

Dickerson, Anne E., "Age differences in functional performance : deficits or artifacts?" (1991). FIU Electronic Theses and Dissertations. 2810.

https://digitalcommons.fiu.edu/etd/2810

This work is brought to you for free and open access by the University Graduate School at FIU Digital Commons. It has been accepted for inclusion in FIU Electronic Theses and Dissertations by an authorized administrator of FIU Digital Commons. For more information, please contact dcc@fiu.edu. 


\section{ABSTRACT OF THE THESIS \\ Age Differences in Functional Performance: \\ Deficits or Artifacts?}

by

Anne E. Dickerson

Florida International University, 1991

Miami, Florida

Professor Paul Foos, Major Professor

An experiment was conducted to compare the functional performance of 20 young adults and 20 older adults in two types of tasks. One type of task was normal activities of daily living which are meaningful, familiar, and well practiced while the other type was a contrived, relatively unfamiliar task of wrapping a package. While young and old adults did not differ in the ratings of the familiarity of the two tasks, results from an Age by Task Type mixed MANOVA demonstrated a significant age difference in both activities. This suggests that older adults show age-related decline with tasks even when those tasks are familiar, practiced, and ecologically valid. 
FLORIDA INTERNATIONAL UNIVERSITY

\author{
Miami, Florida
}

Age Differences in Functional Performance:

Deficits or Artifacts?

A thesis submitted in partial satisfactions of the requirements for the degree of Master of Science in Psychology

by

Anne E. Dickerson 
To Professor Paul Foos, Joan Erber, and Mary Levitt:

This theis, having been approved in respect to form and mechanical execution, is referred to you for judgement upon its substantial merit.

Arthur Herriott, Acting Dean College of Arts and Sciences

The thesis of Anne E. Dickerson is approved.

Joan Erber

Mary Levitt

Paul W. Foos, Major Professor

Date of Examination: April 22, 1991

Richard Campbell

Division of Graduate Studies

Florida International University, 1991 


\section{TABLE OF CONTENTS}

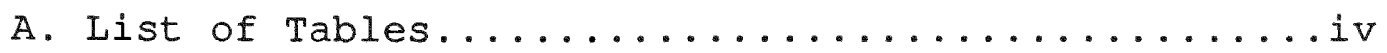

B. List of Figures.................... v

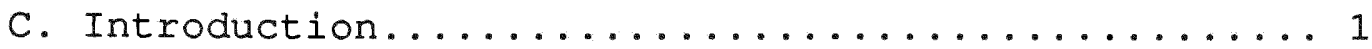

D. Review of the Literature................

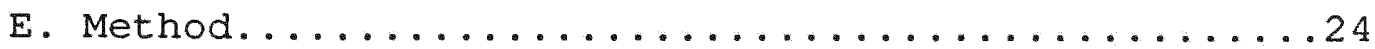

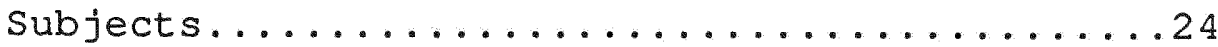

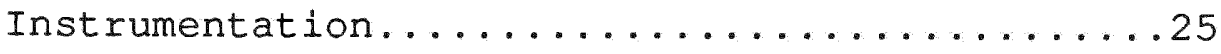

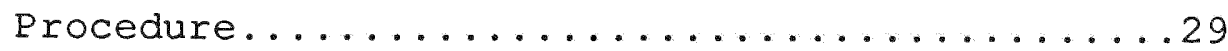

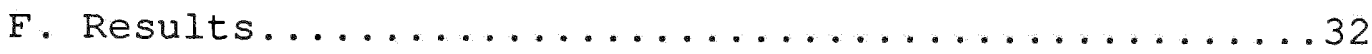

G. Discussion.............................

H. References......................... 43

I. Footnotes.........................49

J. Appendix A. AMPS Scoresheet...............59

Skill Item Example.................63

K. Appendix B. Task Choices...............64

L. Appendix C. Matrix for Scoring Skill Items.....65 


\section{LIST OF TABLES}

1. Familiarity Ratings of Package and ADL Tasks....50

2. Reported Frequency of Performing Package Task

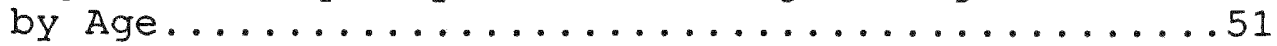

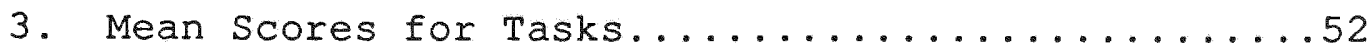

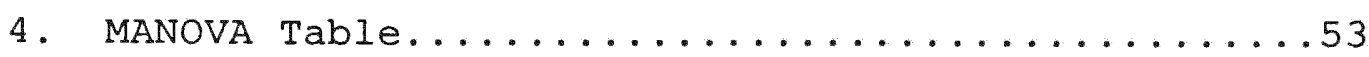

5. Rankings of Tasks According to Difficulty with Many-Faceted Rasch Logit Measure for Motor and

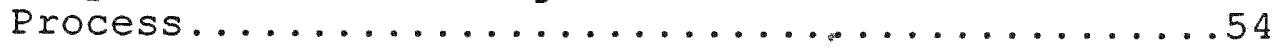




\section{IIST OF FIGURES}

1. Scatterplot of process measures in $A D L$ and

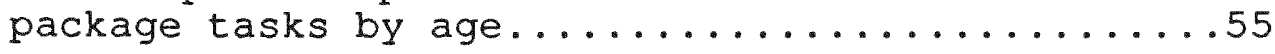

2. Scatterplot of motor measures in ADL and

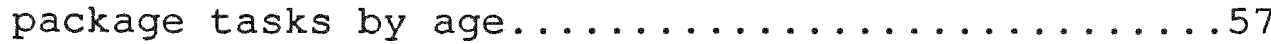




\section{Introduction}

A significant number of research studies have been conducted to identify the effects of aging on motor and process (cognitive) skills, although very few studies have utilized functional performance (i.e., performance in tasks of daily living) as a context of study. This study is based on the assumption that older individuals are likely to have process and motor skills deficits in traditional psychometric tests. However, when test materials are couched in meaningful and exercised tasks, the older adult can compensate for inefficiencies or deficits and perform proficiently.

Functional performance measures are important in aging research for two major reasons. The first is that there is now literature to question the external validity of traditional intelligence and other psychometric test instruments (Akiyama, Akiyama, \& Goodrich, 1985; Baltes \& Willis, 1982; Cavanaugh, 1982; Denney \& Palmer, 1981; Hartley, Harker, \& Walsh, 1980; Salthouse, 1982; Sharp \& Golin, 1987). Assessing individuals in their natural settings should be more generalizable to their ability to process and perform tasks of daily living.

Second, functional performance evaluations are being recognized as superior to the self- or proxy-reports generally used to report physical 
functioning (Guralnik, Branch, Cummings, \& Curb, 1989;

Rubenstein, Schairer, Wieland, \& Kane, 1984). Guralnik et al. underscore the importance of functional performance assessment not only in clinical geriatrics, but in aging research as well. The authors highlight the advantages of the performance report over self report because performance report 1) has greater face validity since it is not compromised by variations in interpretations, 2) has greater reproducibility or reliability, 3) has sensitivity to changes in functioning, 4) is relatively uninfluenced by culture, language, and education, and 5) being less influenced by poor cognitive functioning. Rubinstein et al. found that a group of hospitalized elderly patients tended to overstate their functional abilities while significant others and nursing staff tended to understate their abilities. Therefore, requiring an individual to perform is likely to provide the most accurate picture of function.

This study used a newly developed tool called the Assessment of Motor and Process Skills (AMPS). The AMPS is an observational assessment that simultaneously evaluates the impact of underlying motor and process skills on the ability of the individual to perform functional tasks of daily living (Fisher, 1989). Motor skills are evaluated by observing the posture, 
mobility, coordination, and strength of individuals. Process skills are evaluated by observing the attentional, ideational, organizational, and adaptive processes of the individual through their actions performed during task completion (Fisher, 1989). The logistic Rasch measurement model used with AMPS is one of a group of latent trait measurement models which allows for variation in rater biases, task challenge, and item difficulty.

The AMPS will be used to assess young and old adults' process and motor skills as they perform two activities; one meaningful and familiar task selected by the subject and another relatively unfamiliar task selected by the researcher.

\section{Review of the Literature}

Most will agree that as the body ages, physical capacities decline. There is loss of muscle units, changes in muscle metabolism, and higher thresholds for neural excitation of muscle with age. Along with local limitations in muscular performance, there is an overall decrease in capacity with age (Welford, 1984). A recent study by Stelmach, Amrhein, \& Goggin (1988) suggests that specific aging deficits are present in bimanual coordination processes. Another study by Woollacott, Shumway-Cook, and Nashner (1986) 
demonstrated that older people had impaired postural control under conditions of reduced or conflicting sensory information when compared to younger adults. Other sources (Botwinick, 1984; Kausler, 1982; Levy, 1986) confirm the decrease in each of the sensory modalities; such decreasing capacity means increased demands on the elderly person engaging in functional performance. While deficits in motor skills may be observable during task performance, deficits in process (cognitive) skills are harder to quantify, however, such process deficits could have an impact on the motor output and on task performance. In fact, Fisher (1989) emphasizes that deficits in balance, mobility, coordination, or strength, place increased demand on the individual's adaptive capacities and process skills. If the motor and process skills are decreased, the individual is at risk for losing independence.

It is well documented that older adults have decreased speed in processing information and in performing tasks. Studies indicate that the cognitive systems of young and old adults are similiar, but older adults process information at a slower rate or less efficiently (Hess \& Slaughter, 1986A, 1986B; Puglisi, Park, Smith, \& Dudley, 1988; Simon and Pouraghabagher, 1978; Salthouse \& Prill, 1987, and Salthouse, 1985). Results from two separate studies by Hess and Slaughter 
(1986A, 1986B) in which age differences were found also support the contention that the cognitive system seems to spontaneously organize conceptual information in the same manner for young and old adults. Hess and slaughter suggest that the age-related processing capacity variations limit the older adults' ability to abstract and use conceptual information.

Salthouse and Somberg (1982) also support the idea that, with simple cognitive and perceptual skills, older adults go through the same processing operations as young adults, but at a slower rate. In their study, they had old and young subjects perform four simple tasks for 51 experimental sessions. Although there were still significant age differences (despite considerable improvement with practice), they found that the improvement in performance of both young and old fit the same model and only differed in the absolute levels achieved. However, Salthouse (1985, 1987) suggests that with more complex processes, the speed of processing may affect not only the quantity of responses, but also the quality due to products of earlier operations disintegrating before the later processing can compile the information to use it. Salthouse and Prill (1987) measured inductive reasoning; they found older and younger adults did not differ, except for speed, when determing simple 
relations. However, the older adults were differentiately impaired when relations were complex or when the problems involved alternative organizational patterns. They suggested that the older adults' poorer performance is related to their "inability to process intensely enough to achieve the higher abstractions of alternation and relations among relations" (p. 50).

There is some evidence that speed and quality decrease during middle age, rather then just in old age. Wickens, Brauns, and stokes (1987) had subjects age 20 to 65 perform a series of tasks designed to evaluate the effects of aging on the speed and capacity in processing. They found that information processing speed decreased monotonically and linearly throughout the life span. In another study, Fullerton (1988) investigated age differences in solving series problems requiring integration of new and old information. Scores of the middle aged subjects were significantly lower than scores of young subjects both in their integration and inference, suggesting that deficits in the ability to manipulate items in working memory may decline at a relatively early adult age.

Studies have shown that older adults are vulnerable to the effects of divided attention (Ponds, Brouwer \& Wolffelaar, 1988; MCDowd, 1986; Mitchell \& Perlmuter, 
1986; Plude \& Hoyer, 1986). This is thought to be due to the decreased processing capacity of older adults especially when effortful rather than automatic memory operations are required (Craik \& Byrd, 1982; Hasher \& Zacks, 1979; Mitchell \& Perlmutter, 1986; Wright, 1981). Thus, when performing functional tasks that require one to attend to two or more actions, such as making coffee and toast, older adults may show deficits in skills when compared to young adults.

There are other cognitive processes, such as divergent thinking, deductive reasoning, and problem solving, that are utilized in the performance of daily living tasks. The individual must organize information and use knowledge to accomplish the task. If a problem or error occurs during performance, the individual must use adaptive processes to anticipate, recognize, and/or correct the problem. Studies have demonstrated age differences in such processes.

McCrae, Arenberg, and Costa (1987) studied divergent thinking (i.e., thinking characterized by the production of a number of acceptable solutions to a situation) using cross sectional, longitudinal, and cross sequential analysis. Their studies demonstrated strong evidence for decline in divergent thinking abilities in late adulthood. Thus, the adaptive processing skills may be impaired in the older 
population. Other studies have also shown significant age-related declines in free recall when retrieval demands are increased (Macht \& Bushke, 1983), in deductive reasoning processes (Hartley, 1981), in hypothesis testing questions (Denney, 1985; Hartley \& Anderson, 1983), in encoding specificity (Puglisi, Park, Smith, \& Dudley, 1987), in utilizing encoding strategies (Till, 1985; Bruce and Herman, 1986), in conceptual representation of complex stimuli (Hess \& Walsten, 1987), and in answering inferential questions (Zacks, Hasher, Doren, Hamm, \& Attig, 1987).

While many studies support the hypothesis of a generalized slowing of central processes (Jacewicz \& Hartley, 1987), recent studies go further to specify that performance on nonverbal cognitive tasks involving psychomotor and spatial components show greater age differences than performance on verbal tasks (Berg, Herzog \& Hunt, 1982; Spirduso, 1980; Wickens, Braune \& Stokes, 1987; Salthouse, 1982, 1987; Hale, Myerson \& Wagstaff, 1987; Gaylord \& Marsh, 1975; and Puglisi, 1986). For example, Bruce and Herman (1986) compared young and older adults doing spatial memory tasks. They found older adults did not use effective encoding strategies and concluded that the older subjects needed more experience with the environment than young adults to perform as accurately on spatial memory tasks. 
Since ADL tasks include psychomotor processes and spatial skills, evaluating older adults in instrumental activities of daily living is important for detecting age-related differences in performance.

Although there is not consensus concerning the mechanisms underlying age-related differences, (i.e., whether there is a deficiency in temporal resources, energy, attentional resources, or working memory capacity), all the cited studies have shown significant age-related differences in performance. Most would agree that the locus of these changes is some type of decrease in central rather than peripheral processing. A central processing deficit would affect the older adult's ability to sense and respond to the environment and contribute to the many cognitive aging differences. Therefore, it could be hypothesized that the older adult would demonstrate deficiencies and/or decreases in cognitive performance during functional daily living tasks. However, although these deficits are documented and assumed to be evident with the elderly, they may not be so readily apparent with tasks of daily living. There are other issues that have been identified in studies that highlight some of the limitations of the above hypothesis. These issues are interrelated and will be discussed in terms of 1 ) 
methodology, 2) motivation and ecological validity, 3) practice, and 4) expertise.

First, a study by Ratner, Schell, Crimmons, Mittelman, and Baldinelli (1987) compared the performance in prose recall between college students, noncollege young adults, and older adults. The results demonstrated that the noncollege young adults performed more like the older adults than their college counterparts despite similarities in age and verbal ability. Ratner et al. suggested that memory decline associated with age may result as much from cognitive demands as from biologically determined deterioration. This study casts doubts on studies that have used convenient college students in comparisons with older adults from less cognitively demanding environments.

In a similar type of study, Botwinick and Thompson (1968) demonstrated that when measuring reaction time, there was a significant difference between older adults and athletes. However, there was no significant difference in reaction time between older adults and nonathletes. Botwinick and Thompson suggested that exercise may be more a co-function of the central nervous system rather than an antecedent or cause of the slowdown.

Along the same lines, Spiroduso (1980) reviewed studies concerning physical fitness, aging, and 
psychomotor speed. Spiroduso pointed out that older physically active men are more like younger men than their aged counterparts. He suggested that health may be more related to performance than age. He also underscored the between subject variability in the older adult population.

Others have emphasized the greater variability of older adults compared to the range in a young age group (Baltes, 1987; Baltes \& Willis, 1982; Hale, Smith, Myerson, \& Poon, 1988) possibly due in part to the older adults' varied experiences. Therefore, these "known" age-related differences could possibly be artifacts of individual variation.

Another study exemplifies this possibility. Craik, Byrd, and Swanson (1987) compared memory performance of three elderly samples and one young adult sample. Their results indicated that although there were age-related differences in some of the tests (paired associate and free and cued recall), the differences on the tasks were influenced by the characteristics of the elderly participants. The elderly groups differed in socioeconomic circumstances, levels of verbal ability, and activity level. The tasks were given under conditions of support and nonsupport. The age differences observed were large, small, and nonexistent depending on the interactions 
among tasks, subjects, and materials. Thus, Craik, et al. argue that cognitive performance must be viewed as a function of the particular tasks, participants, and materials used.

Along the same Iines, Kirasic and Allen (1985) offered a framework for conceptualizing research with older adults. They compared the psychometric, experimental, and ecological approaches to studying spatial performance and spatial competence. They make a strong case for using the ecological approach in conjunction with psychometric and experimental methods. Kirasic and Allen state that age-related decrements are often seen in studies involving abstract components and unfamiliar contexts. It is not clear whether decrements would be seen in real life situations. Their conceptual framework requires that research with older adults consider the 1) individual characteristics (including processing abilities, personality variables, physical attributes, and neurological states), 2) situations (what tasks and in what settings), and 3) adaptive processes (cognitive activities necessary for performance).

One variable that seems to affect an older adult's performance is motivation. Hulicka (1967) reported a high drop out rate with elderly subjects when presenting unfamiliar and nonsense syllables. He 
concluded that older adults need and want tasks that are meaningful and relevant. Botwinick (1984) notes that the elderly are disproportionately benefited when material is relevant and familiar. However, this may not always be true. Foos (1989) compared the recognition memory performance of old and young adults in a nonlaboratory setting using the common, everyday items of a pushbutton telephone dial and the top side of a United States penny. He found that older adults had more incorrect responses, but were more confident in their responses than the young adults. Thus, his study supports the external validity of laboratory results in recognition memory.

In another study, Adams and Rebok (1982-3) suggested that problem solving ability may not be related to age, but to deficiencies in the environment. Two groups of older adults were compared doing an ismorphic inquiry problem. One group had no instruction and the other had instruction on how to best plan and prepare questions. The group given planning instruction performed better than the group with no instruction, but there was no significant difference on the transfer task. The authors suggest that megacognitive strategy deficiencies are at least in part responsible for deficits in problem solving in later life and megacognitive training may lead to 
improved task performance. The participants did not lack the capability of strategic planning and deliberate search, but failed to initiate operations without inducement. Adams and Rebok proposed that motivational factors may affect performance when the tasks are meaningless or when self regulatory activities like note-taking are seen as admissions of failure rather than as effective strategies for solving problems. Therefore, they support the contention that when examining megacognitive activity, it is important to take the sociohistorical context of the older adult into account.

Others have recently questioned the ecological validity of traditional experimental tasks. Sharp and Gollin (1987) compared the spatial memory of young and old adults on two tasks; on one common objects were displayed on a map and on another objects were displayed in a "real life" room. The older adults had lower spatial memory in the map condition than young adults, but performed just as well as the young in the room condition. Sharp and Gollin hypothesize that age-related decline for spatial memory is not a characteristic of aging, per se, but derives from an interaction of age and task conditions. They indicated that the visual distinctiveness between the two conditions made the difference. They further 
suggested that the elderly may be better in spatial memory in the real world because the visual distinctiveness of their everyday environment in contrast to many lab or clinical tests. They further emphasize the need to assess the older adults in their typical environment.

Akiyama et al. (1985) compared fifth grade, ninth grade, college students, and older adults on spatial ability measured using three pencil-and-paper tasks. Two tasks involved drawing water lines on both a tilted water bottle on a horizontal stand and a tilted water bottle on a tilted stand. The third task involved giving directions from one place to another on a hypothetical map. The older adults' performance was equal to that of the college students when drawing the line on the bottle on the horizontal stand, but poorer than that of young adults when drawing a line when the bottle was on a tilted stand. However, on the third task, giving directions, older adults performed better in terms of accuracy (use of compass points) and completeness (all departing, arriving, and turning directions are given) than college students. One way to explain the tilted water results is that the task requires integration of two cues. Another explanation offered by Akiyama et al. is in terms of ecological validity of the tasks. Observation of water lines in 
real life is almost always in a horizontal plane. Thus, when the task was more ecologically valid, the detrimental effect of age was not observed. This explanation is supported by the results of the direction-giving task since the older adult likely has had more experience giving directions.

Denney (1982, 1985) has questioned the ecological validity of studies. She found that elderly adults have the ability to use more efficient constraint-seeking strategy on a Twenty Question Task, but they do not use it spontaneously (Denney, 1985). In a review of problem solving studies, she concluded that age differences are probably a result of both age change effects and cohort difference effects (Denney, 1985). Denney believes poor performance exhibited by the elderly is a result of cognitive rather than noncognitive variables. She proposed a model of life span development that integrates these findings (Denney, 1982). Her framework makes a distinction between unexercised abilities which are a function of biological potential and the normal environment, and optimally exercised abilities, which are frequently utilized and therefore performed at the highest level possible. The performance level for any one skill depends on the amount of exercise and/or training one has experienced. Abilities that are not frequently 
exercised will follow the curve for unexercised ability. Thus, the argument can be made that older adults do not do as well in lab situations because traditional psychometric tests measure unexercised cognitive abilities that college students are routinely using in their educational pursuits. A study by Denney and Palmer (1981) presented two types of problem solving tasks, one typically used in experimental research and one composed of practical situations. The study demonstrated that in traditional problem solving tasks, performance decreased linearly with age. However, performance on the practical tasks increased to a peak in the 40-50 year olds and declined later. The outcome of the study demonstrates that performance on practical problems may exhibit a different relationship with age.

Others have questioned whether traditional tests are appropriate for older adults. Baltes and Willis (1982) argue that many older adults don't live in environments in which the cognitive abilities tested by traditional intelligence tests are relevant. They stress the intraindividual plasticity in older adults and question whether performance on a intelligence test is important to the lives of the elderly.

Others support this same idea that the environment is a major factor in cognitive performance. A study by 
Labouvie-Vief and Gonda (1976) demonstrated that elderly women could raise and maintain their cognitive performance when trained in covert self monitoring strategies. The authors support that arguement that there is plasticity in old age rather than viewing intellectual aging decrements as irreversible and suggest that environmental contingencies play a role in modifying performance levels.

In line with the concept of unexercised and exercised abilities, is the study of expertise. Salthouse (1985) and others (Rybash, Hoyer, \& Rooden, 1986) suggest that extensive experience or expertise can compensate or overshadow the negative effects of aging in efficiency of functioning. Salthouse (1985) further suggests that because practice contributes to changes in efficiency, it may be impossible to predict real world functioning on the basis of lab performance; that is, performance on lab tasks may not be generalizable to well practiced activities. It may be that differing degrees of experience (practice) contribute to discrepancies in 1) age trends in different types of behavior and 2) age trends in laboratory and real world experiments (Salthouse, 1985). Perhaps the best example of this type of discrepancy is in salthouse's classic study of typists. Salthouse found that older typists had decreased 
reaction times, but that they still maintained rates of typing that were independent of age. The implication is that the older typists develop compensatory mechanisms that allow them to maintain a high level of typing proficiency despite declines in speed of perceptual and motor processes (Salthouse, 1985).

Expert knowledge has often been described as domain specific, automatic, and intuitive (Rybash et al., 1986). The expert or skilled performer is able to produce precise behavior with the least amount of effort, is quicker to detect and correct errors, and can adapt to a variety of situations while still performing optimally. Because experts can perform with less attentional demands, they are more resistant to distraction from outside resources and better able to handle two activities simultaneously (Salthouse, 1985).

Salthouse (1985) has developed a taxonomy of explanatory mechanism to describe the nature of skill and expertise. These elements are closely related to the descriptors of performance in the AMPS and thus each element is summarized below to as how the expert differs from the unskilled novice.

Component Efficiency - Experts complete a given processing operation in a shorter amount of time and have better quality of operation. 
Component Identity - An expert is able to identify and substitute a new component that has the advantages of shorter time, increased precision, and decreased demands of attention in a sequence while the unskilled performer would not change the processing. Sequence Order (assuming more than one component) - With experience, one learns to use the most effective or efficient method of performing a task; the expert would use the best method of which they are capable. Sequence mode - Experts and novices differ in the mode of executing components. Experts execute certain processing components only after particular outcomes of prior components occur or because of assumed greater residual attentional capacity, they are able to perform one or more activities simultaneously because of some type of parallel processing. Sequence Availability - When the sequence of procedural components are automatic and independent of conscious control, the expert can maintain consistent levels of performance despite varying environmental conditions. That is, the previously laborious processes become subroutines. 
Sequence Repertoire - Someone with a greater repertoire of possible pathways to the same goal will produce superior performance to a person with only one fixed method. Sequence Selection - The expert can adapt a procedure optimally suited to a particular situation, (i.e., the efficiency of strategy).

Sequence Assembly - Experts are more effective in devising and constructing optimal sequences of processing components. Working Memory Capacity - Experience with particular tasks probably improves the efficiency with which information may be coded in the limited capacity system (not increasing basic working memory capability). The amount and organization of information possessed by the individual affects the efficiency with which material can be entered and retrieved from long term storage. Knowledge Representation - The expert uses important relationships among relevant task elements and therefore high quality representations are likely to suggest appropriate action sequences to task selection. 
Knowledge Quality - Experts have finely differentiated information and information is more accurate.

Knowledge Quantity - Experts possess more relevant information to their particular specialty and that information is domain specific.

Knowledge Organization - Experts' domain specific knowledge is organized according to structural principles or functional relationships which allows for more efficient and deeper comprehension of intermediate problems.

Arousal Level - Experts use appropriate level of arousal for tasks at hand.

Attentional Capacity - Experience does not increase attentional capacity, but may free attentional demands. Basic Operational Time - Individuals differing in their rate of processing would likely produce varying levels of performance.

In summary, there is evidence for age-related decline in processing capability and capacity that may lead to deficiencies in performance with increased age. However, there is also evidence that limits the 
generalizability of results from performance on lab tasks to normal daily living tasks. In daily living tasks, motivational factors, ecological validity of testing, variability of performance of older adults, the effect of practice on abilities, and expert knowledge and ability must all be taken into consideration.

The objective of this study is to compare the performance of older adults on meaningful and practiced activities on which they are "expert" and the performance of the same group on an unfamiliar, contrived activity. Such a comparison will be made using an assessment tool that measures underlying process and motor skills (the process skill items coinciding with salthouse's taxonomy) used by older adults in their performance of normal daily living tasks. Based on the literature concerning age related decrements in cogntive skills, practice, ecological validity of tests, and expertise, it is hypothesized that older adults and young adults will not show significant differences in their performance (i.e., process and motor skills as identified by the AMPS) on the familiar activity. However, there will be a significant difference between the old and young adults' performance on the unfamiliar or contrived activity; the older adults' performance will be 
significantly lower than young adults'. That is, there will be an interaction effect of age and task type.

If an Age x Task Type interaction is established, this study will support the notion that although older adults may show deficits in traditional psychometrics measurements, they can compensate with experience and expertise with ecologically valid tasks. However, if the older adults are significantly different from young adults on both familiar and unfamiliar tasks, this study would than support the position that age-related deficits impact on older adults processing abilities in all tasks since the motivational, experiential, and ecologically validity components are taken into account with this assessment.

\section{METHOD}

$\underline{\text { Subjects }}$

Subjects were 40 English-speaking females, consisting of 20 community living healthy elderly volunteers between 57 and 84 years of age $(\underline{M}=71.3, \underline{S D}$ $=7.17$ ) and 20 community living young adults between 20 and 35 years of age $(\underline{M}=27.7, \underline{S D}=4.92)$. Individuals with a history of significant orthopedic, neurological, or psychosocial problems were excluded. Subjects were recruited through letter and telephone requests and were not paid for their participation. The mean 
educational level for young adults was 15.80 years (SD $=2.12$ ) while the older adults was 14.95 years $(\underline{S D}=$ 2.44) which was not significantly different $\underline{t}(38)=$ 1.18 .

\section{Instrumentation}

The instrument used in this study is the Assessment of Motor and Process Skills (AMPS). It is a criterion referenced observation assessment that evaluates an individual's ability to organize and execute a daily living task as shown by effective, efficient, and timely completion of a specified task (Fisher, 1989).

The score sheet for the this assessment is included in Appendix $A$ along with a sample of scoring for one of the skill items. The skill items and tasks have been carefully developed and refined through a series of pilot studies on older adults (ages 64 to 86). The pilot studies included development of a table of specifications, content validation of the items and tasks by panels of experts, and examination of reliability (internal consistency and interrater) and content validity of the scales. (Fisher, 1989; Fisher \& Hopp, 1990; Fisher \& Kielhofner, 1989). The test manual is available from Dr. Anne Fisher, Department of 
Occupational Therapy, University of Illinois at Chicago.

The many-faceted Rasch measurement model, utilized through the FACETS computer program, (Linacre, 1989) is being used to develop the AMPS. It is an expansion of the single Rasch measurement model which provides a theory for 1) item analysis and selection and 2) a measurement scale for reporting scores (Isaac \& Michael, 1984). The model is based on the idea that a valid measurement is derived from the function of multi attributes or parameters. It is the stochastic or probabilistic equivalent of Guttman scaling such that Rasch probabilities are Guttman ordered (Fisher \& Hopp, 1990) .

The many-faceted Rasch model provides the framework from which difficulty of the skill items, the challenge of the tasks, and the severity of the rater are examined and accounted for by constructing a single common variable from which each facet is measured (Fisher, 1989). This is called the calibration process. Items are calibrated according to their difficulty and represent positions along a linear scale. This scale represents an abstract continuum of ability. Tasks are calibrated along the same linear continuum based on their relative challenge. Therefore, linear adjustments for item difficulty can 
be made depending on the challenge of the task performed. Similarly, raters are calibrated according to their severity of rating, enabling scores to be adjusted for the rater's personal biases and perceptions. That is, when an individual is evaluated using the AMPS, his or her performance is judged relative to the difficulty of the items, challenge of the tasks, and severity of the rater. Thus, through the Rasch analysis, the assessment is sample-free and test-free. Moreover, since all of these are calibrated on the same linear scale, it is possible to compare and predict performance across tasks or items of greater or lesser difficulty that are not actually performed (Fisher, 1989). In other words, through the FACETS computer program, the model corrects for differences among raters due to personal biases and perceptions, variation in the challenge of the task, and difficulty of the test item (Fisher \& Hopp, 1990). Evaluation of validity and reliability is based on examination of the results of the analysis for skill items, tasks, raters, or subjects that "misfit" when observed values are compared to values expected by the measurement model. A misfit is an unexpected response within the measurement model. For example, if a specific rater scores a particular item more strictly than other items, that rater-item interaction will 
misfit. When these deviations are identified, their effect on the estimation of the subject's ability can be adjusted (Fisher, 1989).

The Rasch output gives an internal consistency reliability coefficient that is equivalent to Cronbach's coefficient alpha or Kuder Richardson 20 (KR 20) for dichotomous data (Fisher \& Kielhofner, 1989). Reliability is also evaluated based on standard error of measurement (<.5 logit). Validity, in Rasch analysis, is based on the fit of items, activities, raters, and subjects to the measurement model (Fisher \& Kielhofner, 1989).

Preliminary studies have shown the AMPS to have acceptable reliability (Fisher \& Hopp, 1990). Specifically, with a study involving older adults, the many-faceted equivalent of Cronbach's alpha revealed an internal consistency reliability of .94 for the motor scale and .92 for process scale items. The internal consistency for the tasks was .96 and .94 for motor and process scales respectively (Fisher \& Hopp, 1990). Raters were found to differ significantly ${\left(\underline{x}^{2}\right.}^{2}$ $\geq 105 ; \underline{p} .001$ ) in severity, however, the raters were very consistent when rater severity was taken into account. Rater agreement on both scales was $95 \frac{\circ}{5}$ with a probability of a misfit rating set at $\leq .10$. 
Since this investigator has been involved in developing the AMPS, she has been calibrated as a rater. She has been able to use the reference group already established at the University of Illinois at Chicago. The reference group is 100 to 200 subjects tested by the American Occupational Therapy Association / American Occupational Ther"apy Foundation's gerontology symposium research team members. This comparison is possible because the investigator was calibrated through a process of scoring 10 video taped observations that were also scored by other members of the research team. Thus, the subjects tested in this study were linked to the AMPS data.

\section{Procedure}

Each subject was videotaped in her home performing two familiar activities of daily living $(A D L)$ and one unfamiliar, contrived activity following established test guidelines. Half of the participants in each age group were randomly assigned to do the two familiar ADL tasks first and the other half was assigned to do the unfamiliar activity first.

Because motivational and experiential factors may influence the quality of performance, each subject selected the two familiar ADL tasks to perform from the list of calibrated activities (see Appendix B). Each 
subject also performed the relatively unfamiliar, contrived task. This task, identical for all subjects, was preparing a package for postal mail. Specifically, the activity consisted of wrapping two glass drinking containers and two small square boxes in a $10 " \mathrm{x} 12$ " $\mathrm{x}$ 5" box. The subjects were required to use a brown paper grocery bag as the outside cover, use mailing tape, and address the mailing label to a family member. The researcher provided all materials for the package except for scissors, a pen, and the grocery bag and newspaper for subjects who had them readily available. Previous to the start of the task, subjects were told that the package would not be sent but that they should wrap the package as if they were going to mail it through the United States Postal Service.

Subjects were given the same directions for all tasks. They were told to do the tasks as they would normally perform them and clean up the work area after finishing the task. If the subjects had questions about how to wrap the package, they were told to do what they would normally do.

After completion of the three tasks, subjects were instructed to rate the familiarity of the tasks they performed on a 5-point Likert scale ("1" was "unfamiliar, never do this activity"; "5" was "familiar, do this activity frequently"). Subjects 
were also asked how frequently they would perform the package task in the course of their normal daily routines. The ratings for the two familiar ADL tasks were averaged. The familiarity ratings were analyzed in a 2 (age) $\times 2$ (task type) mixed anaylsis of variance (ANOVA) with age as the between-group variable and task type as the within-subject variable. There was a significant ANOVA main effect for task type $\underline{F}(1,38)=$ $58.45, \underline{p}<.0001$ which indicates that the two tasks were significantly different in terms of familiarity. Since the age variable did not reach significance $\underline{F}(1,38)=$ $.04, \underline{p}<.834$ nor did the Age $\mathrm{x}$ Task Type interaction $\underline{F}(1,38)=1.77, \underline{p}<.192$, it can be concluded that the young and old adults rated the familiarity of tasks similiarly. That is, in general, both young and old adults rated the ADL tasks as familiar and significantly different from the unfamiliar package task. Additionally, there was not a significant difference between old and young adults in the reported frequency of performing the package task during normal daily living; $\underline{x}^{2}(6, N=40)=5.98, \underline{p}<.43$ (see Table 2).

Once videotaped, the subjects were rated on 35 AMPS skill items that assess the various motor and process skills. The grading scale is based on the matrix exhibited in Appendix C. 
The investigator rated all the videotapes of the 120 tasks ( 40 subjects $\times 3$ tasks). Although this may initially be seen as a limiting factor of the study, the Rasch measurement model identifies unexpected responses and therefore controls for irratic or inaccurate ratings on individual items. Three other calibrated observors rated 31, 18, and 14 observations. The many-faceted Rasch anaylsis generates a fit statistic which is an index of internal consistency in scoring performance of each rater. All four raters were internally consistent with an overall percent of rater agreement of indvidual item scores of $94.8 \%$ for the ADL activities and $95.4 \%$ for the package. The number of misfit ratings was consistent with the model expectation.

\section{Results}

The AMPS yielded four scores (i.e., dependent measures) for each subject; a process and a motor score for the familiar ADL task and a process and motor score for the unfamiliar, contrived package. See Table 3 for the means of each of these scores. These four measures were analyzed in an Age x Task Type mixed multivariate analysis of variance (MANOVA) with age as a between-group variable and task type as the within-subject variable. For results that reached 
significance on the MANOVA, the process and motor univariates were inspected.

The was a signifcant MANOVA main effect for age $\underline{E}(2,37)=12.08, \underline{p}<.001$ (see Table 4). Both univariate dependent measures (i.e., process and motor) were significant. Older subjects performed significantly lower on both the process $E(1,38)=9.95, \underline{p}<.003$ (young, $\underline{M}=2.11 ;$ older, $\underline{M}=1.56$ ) and on the motor $\underline{F}(1,38)=23.73, \underline{p}<.001$ (young, $\underline{M}=4.84 ;$ old, $\underline{M}=$ 3.25) dependent measures. The scatterplots in Figure 1 and 2 illustrate the distribution of subjects on the two dependent measures for both tasks. Older adults tended to be grouped on the lower end of the scales while the young adults tended to fall on the upper end. However, in both plots, young and old subjects overlap in their scores. That is, there were older subjects who performed as well as or better than some of the young adult subjects.

There was a nonsignificant MANOVA main effect for task $\underline{E}(2,37)=0.49$. The subjects did not differ significantly in how they performed in ADL tasks (M $=$ 1.84) from the package task $(\underline{M}=1.83)$. This result is expected because of the many-faceted Rasch anaylsis adjusts the ability measure for the subject to take into account the level of difficulty of the activity performed. 1 Rasch does rank the tasks in terms of 
their level of difficulty and in both measures, process and motor, the package was the most difficult task (see Table 5) performed. If the process and motor scores were not anchored for difficulty in the many-faceted Rasch analysis, a significant main effect for task would be present. However, more importantly, the relative positions of the subject's scores remain the same on the linear continuum of ability regardless of whether scores are anchored or unanchored for difficulty. In this study, anchored scores were utilized.

The MANOVA did not reach significance for the interaction effect of Age $x$ Task $\underline{E}(2,37)=2.05$, which means that both young and old adults demonstrated a similiar pattern of performance. This was particularly true with respect to the process dependent measure $\underline{F}(1,38)=1.20$. However, the motor dependent measure approaches significance at $\underline{F}(1,38)=3.44, \underline{p}<.072$ which suggests the possiblity that age shows a different relationship with respect to familiar and unfamiliar tasks in terms of motor skills.

\section{Discussion}

Results of this study indicate that older adults have age-related deficits of both a cognitive and motor nature. 
As expected, young subjects performed significantly better on a task that was relatively unfamiliar and unpracticed (package). This result replicates the typical laboratory findings of young adults' superior performance over older adults.

Young subjects also performed significantly better than old with the ADL tasks which were rated as familiar, meaningful, and practiced by both age groups. This finding suggests that even with ecologically valid tasks (i.e., familiar tasks older adults have chosen to perform), age-related decline is still demonstrated. It has been hypothesized that young adults are at an unfair advantage in traditional laboratory experiments since the experimental tasks are often unfamiliar, unmotivating, and/or exercise abilities that older adults do not typically utilize compared to the college students used as subjects. Thus, age-related difference results have been questioned in terms of their external validity. In this experiment, young and old adults were compared on activities of daily living that were familiar, meaningful, and exercised for both groups; in fact, older adults tended to rate the ADL tasks as more familiar, though not significantly so. Further, the tasks were salient to young and old adults in that they were allowed to select which activities they would perform. It could be argued that although 
the subjects were given a choice of activities, they were limited in this choice and therefore had limited motivation for making their bed or making a salad under the test conditions. Although this may be a possible argument for the tasks not being meaningful, it seems unlikely that that young and old adults would be differentiately affected by the motivational factor. That is, young adults should be just as likely to find the tasks unmotivating and unmeaningful as the older adults. The activities were performed in the subjects' home, thus eliminating the impact of a new or foreign environment on the older adults' performance. Also, many of the subjects arranged the tasks to be done at the normal time of occurance during their daily routine. For example, subjects made a salad for the study that they planned to then serve that evening. The fact that older adults still performed significantly lower than young adults despite the ecological conditions, suggests that age-related differences found in aging studies are not artifacts of the laboratory experiment.

Further, this study does not support the concept that expertise or practice can compensate for age-related decline, at least for those activities used in this study. This was particularly true for the process measure, which is of significant interest since 
the AMPS process skill items are of a more organizational/adaptive nature than other cognitive measures. That is, the process skill items not only focus on how individuals sequence or organize the elements of a task, but also on how they adjust or accommodate to problems during the task. Assuming older adults have performed ADL tasks for more years than young adults, they should be more "expert" in such tasks. Such expertise should give the older adult an advantage in performance (Salthouse, 1985; Denney, 1982). However, this was not shown to be the case in this study. It may be that practice over long periods of time for these kinds of activities are not differentially beneficial for the older adult. There are two possible reasons for this. First, it may be that activities of daily living are not tasks that change with practice or expertise because they are overlearned or too familiar. Individuals learn how to make a bed or make a sandwich very early in life and as creatures of habit, may not think about how to change their performance patterns to be more efficient or effective unless forced to do so. This would be different from Salthouse's (1985) older typists who, for job security, were compelled to develop compensatory mechanisms to maintain high rates of typing despite declines in perceptual and motor 
processes. Thus, older adults may not develop compensatory mechanisms for tasks of daily living when cognitive and motor deficits occur as they might for other types of tasks.

A second possible reason that older adults did not demonstrate a practice or expertise effect for daily living tasks is that there may be a ceiling effect for practice on ADL tasks. That is, because these tasks are learned early, young adults may already have benefited from practice and therefore, could also be considered "experts" in such tasks. Although this is likely to be true in a general sense, the variability of scores within young and old subjects and the fact that no young or old subject attained maximum scores in both the process and motor components of the AMPS would suggest that there is not a ceiling effect.

It could be argued that there was no Age $x$ Task interaction effect because of the choice of the package as an unfamiliar, contrived activity by the experimenter. Although rated as significantly different from the ADL tasks in terms of familiarity, it still is an activity that most individuals have performed even if only a few times a year. If people do not show increasing ability from practice and/or expertise with daily living tasks, the package may have not been unfamiliar enough to elicit an interaction 
effect. However, even if the package was too familiar, the results still support the major finding that older adults show age-related deficits with cognitive and motor performance.

On the other hand, there was some evidence that the package was indeed an unfamiliar, unmotivating activity. That the age $\mathrm{x}$ task univariate motor measure shows a trend toward significance. For the package task, the researcher provided the tape to bind the package. It was a clear, sticky tape with no device to cut the edges, as with most tape dispensers. Many subjects, but particularly the elderly, had much difficulty manipulating this tape (thus scoring lower on some motor skill items). They commented that they have never used this kind of tape before, and made it clear that they did not like this activity. Although it cannot be determined that the trend toward an interaction effect in the motor measure was due to the unfamiliarity of the tape mechanism, this anecdotal information suggests the need for further research. A future study with a task totally foreign to subjects (much like nonsense words being used in memory studies) would possibly elicit an interaction effect. However, it should be clearly noted that if the results of such a study were in line with this present study, an interaction effect would mean that older adults 
demonstrate age-related deficits with familiar, practiced tasks and even greater deficits with unfamiliar, unpracticed tasks.

The results of the study demonstrated individual variability of performance. Although there is a significant age effect, the scatterplots for both motor and process measures indicate that some of the older subjects did just as well or better than some of the younger subjects. Further, some subjects performed better on the package than on the ADL tasks. An important next step to this research would be to determine the basis for the individual variability of performance. Several lines of research may need to be pursued. First, the effect of familiarity and/or practice on performance should be examined further. Regardless of age, activities that are considered familiar/practiced should be compared to unfamiliar/unpracticed. Using the AMPS's list of calibrated activities, subjects could select and perform the most familiar tasks and perform a totally unfamiliar/unpracticed task as suggested previously. Then, through individual analysis of the AMPS skill items it could be determined which constructs (i.e., skill items) are affected by the difference in familiarity/practice. It may be that only motor skills or only specific motor or process skill items are 
impacted when the task is unfamiliar. Identifying specific items would provide insight into how and why familiarity or practice affects performance.

Another line of research may be to examine the effect of motivation on performance. That is, does a person who chooses a task to perform do better than someone who is assigned a task to perform. If it is assumed that an individual would chose a familiar/practiced activity, this study would be similiar to the one just previously mentioned.

An important study would be to ask individuals to perform the same activities over a period of time and thus examine how performance evolves over the lifespan. In such a longitudinal study, one would examine the skill items individually and attempt to understand specific processes in the pattern of changes in performance. Such a study would explain some of the subject variability in this study. For example, do the older adults who performed lower than the young adults do so because they have always had lower ability or at some point in time did they lose specific abilities. In summary, older adults demonstrated poorer performance on an unfamiliar, contrived package task and on activities of daily living that they rated as very familiar and practiced even when those activities were selected by the individuals and performed in their 
familiar home environments. Thus, this study supports the hypothesis that older adults demonstrate age-related decline even with activities that take motivational, experiental, and ecological validity components into account. This outcome supports the external validity of laboratory studies that find older adults' performance below the level of young adults. 


\section{References}

Adams, C.C. \& Rebok, G.W. (1982-3). Planfulness and problem solving in older adults. International Journal of Aging and Human Development, $16, \frac{17271-281 .}{2}$

Akiyama, M.M.; Akiyama, A., \& Goodrich, G.C. (1985). Spatial development across the life span. International Journal of Aging and Human Development, 21, 175-185.

Baltes, P.B. (1987). Theoretical propositions of life-span development psychology: On the dynamics between growth and decline, Developmental Psychology, 23, 611-626.

Baltes, P.B. \& Willis, S.L. (1982). Plasticity and enhancement of intellectural functioning in old age. In Craik, F.I.M. \& Trenub, S. (Eds.), Aging and Cognitive Processes (pp.353-385). New York: Plenum Press.

Berg, C., Hertzog, C., \& Hunt, E. (1982). Age differences in the speed of mental rotation. Developmental Psychology, 18, 95-107.

Botwinick, J. (1984). Aging and Behavior, 3rd edition, New York: Springer.

Botwinick, J. \& Thompson, L. W. (1987). Age difference in reaction time: An artifact? The Gerontologist, 8, 25-27.

Bruce, P.R. \& Herman, J.F. (1986). Adult age differences in spatial memory: effects of distinctiveness and repeated experience. Journal of Gerontology, 4, 774-777.

Cavanaugh, J. (1982). Memory in everyday life. The Gerontologist, 22, 206.

Craik, F.I.M. \& Byrd, M. (1982). Aging and cognitive deficits. In Craik, F.I.M. \& Trenub, S. (Eds.), Aging and Cognitive Processes (pp. 191-209). New York: Plenum Press.

Craik, F.I.M.; Byrd, M.; \& Swanson, J.M. (1987). Patterns of memory loss in three elderly samples. Psychology and Aging, 2, 79-86.

Denney, N.W. (1982). Aging in cognitive changes. In Wohlman, B.B. (Ed.), Handbook of Developmental Psychology (pp.807-827). Englewood Cliffs, NJ: Prentice-Hall. 
Denney, N.W. (1985). A review of life span research with the twenty questions task: a study of problem solving ability. Aging and Human Development, 21, 161-173.

Denney, N.W. \& Palmer, A.M. (1981). Adult age differences on traditional and practical problem-solving measures. Journal of Gerontology, 30, 323-328.

Fisher, A. G. (1989). Assessment of Motor and Process Skills, Draft version 4 .

Fisher, A.G. \& Hopp, J.F. (1990). Assessment of Motor and Process Skills, unpublished manuscript.

Fisher, A. G. \& Kielhofner, G. W. (April 18, 1989). Assessing process skills in the developmentally disabled. American Occupational Therapy Annual Conference.

Foos, P.W. (1989). Age differences in memory for two common objects. Journal of Gerontology: Psychological Sciences, 44, P178-180.

Fullerton, A.M. (1988). Adult age differences in solving series problems requiring integration of old and new information. Aging and Human Development, 26, 147-155.

Guralnik, J.M.; Branch, L.G.; Cummings, S.R.; \& Curb, J.D. (1989). Physical performance measures in aging research. Journal of Gerontology, 44, M141-146.

Gaylord, S.A. \& Marsh, G.R. (1975). Age differences in the speed of a spatial cognitive process. Journal of Gerontology, 30, 674-678.

Hale, S., Myerson, J. \& Wagstaff, D. (1987). General slowing of nonverbal information processing: evidence for a power law. Journal of Gerontology, 42, 131-136.

Hale, S., Smith, G., Myerson, J., \& Poon, L. (1988). Age, variability, and speed: Between Subjects Diversity. Psychology and Aging, 3, 407-410.

Hartley, A. (1981). Adult age differences in deductive reasoning processes. Journal of Gerontology, 36, $700-706$.

Hartley, A.A. \& Anderson, J.W. (1983). Task complexity and problem-solving performance in younger and older adults. Journal of Gerontology, 38, 72-77. 
Hartley, J., Harker, J., \& Walsh, D. (1980). Contemporary issues and new directions in adult development of learning and memory. In L.W. Poon (Ed.), Aging in the 1980's: Psychological Issues (pp. 239-252). Washington, DC: American Psychological Association.

Hasher, L. \& Zacks, R. (1979). Automatic and effortful processes in memory. Experimental Psychology, 108, $356-388$.

Hess, T.M. \& Slaughter, S.J. (1986a). Aging effects on prototype abstraction and concept identification. Journal of Gerontology, 41, 214-221.

Hess, T.A. \& Slaughter, S. J. (1986b). Specific exemplar retention and prototype abstraction in young and old adults. Psychology and Aging, 1, 202-207.

Hess, T.M. \& Wallsten, S.M. (1987). Age differences in the perception and learning of artisitc categories. Psychology and Agning, 2, 243-253.

Hulicka, I.M. (1967). Age differences in retention as a function of interference. Journal of Gerontology, 22, 180-184.

Isaac, S. \& Michael, W.B. (1984). Handbook in Research and Evaluation. San Diego: Edits Publishers.

Jacewicz, M.M. \& Hartley, A.A. (1987). Age differences in the speed of cognitive operations: resolution of inconsistent findings. Journal of Gerontology, 42, 86-88.

Kausler, D.H. (1982). Experimental Psychology and Human Aging. New York: Wiley.

Kirasic, C.C. \& Allen, G.L. (1985). Aging, spatial performance and spatial competence. In Charness, $N$. (Ed.), In Aging and Human Performance (191-217). New York: Wiley.

Labouvie-Vief, G. \& Gonda, J.N. (1976). Cognitive strategy training and intellectual performance in the elderly. Journal of Gerontology, 31, 327-332.

Linacre, J.M. (1989). FACETS: Computer program for many-faceted Rasch measurement. Chicago: MESA.

Levy, L.L. (1986). Sensory Changes and Compensation. In Davis, L. \& Kirkland, M. (Eds.), The Role of Occupational Therapy with the Elderly (pp.49-68). Rockville, Maryland: American Occupational Therapy Association, 49-67. 
Macht, M. \& Bushke, H. (1983). Age differences in cognitive effort in recall. Journal of Gerontology, 38, 695-700.

Mitchell, D.B. \& Perlmutter, M. (1986). Semantic activation and episodic memory: age similarities and differences. Developmental Psychology, 22, 86-94.

McCrae, R.R., Arenberg, D. \& Costa, P.T. (1987). Declines in divergent thinking with age: cross sectional, longitudinal, and cross sequential analysis. Psychology and Aging, 2, 130-137.

MCDowd, J.M. (1986). The effects of age and extended practice on divided attention performance. Journal of Gerontology, 41, 764-769.

Plude, D.J. \& Hoyer, W.J. (1986). Age and the selectivity of visual information processessing. Journal of Psychology and Aging, $1,4-10$.

Ponds, R.E., Brouwer, W.H., \& Wolffelaar, P.C. (1988). Age differences in divided attention in a simulated driving task. Journal of Gerontology, 43, 151-156.

Puglisi, T. (1986). Age related slowing in memory search for three dimensional objects. Journal of Gerontology, $41,72-78$.

Puglisi, J.T. \& Park, D. C. (1987). Perceptual elaboration and memory in older adults. Journal of Gerontology, 42, $160-162$.

Puglisi, J.T., Park, D.C., Smith, A.D., \& Dudley, W.N. (1988). Age differences in encoding specificity. Journal of Gerontology, 43, 145-150.

Ratner, H.H.; Schell, D.A.; Crimmins, A.; Mittelman, D.; \& Baldinelli, C. (1987). Changes in adults' prose recall: Aging or cognitive demands. Developmental Psychology, $23,521-525$.

Rybash, J.M.; Hoyer, W.J.; \& Roodin, P.A. (1986). Adult Cognitive and Aging. New York: Pergamon Press.

Rubenstein, L.Z.; Schairer, C.; Wieland, G.D.; and Kane, R. (1984). Systematic biases in functinal status assessment of elderly adults: Effects of different data sources. Journal of Gerontology, 39, 686-691. 
Salthouse, T.A. (1982). Adult Cognition. New York:

Springer-Verlag.

Salthouse, T.A. (1985). A Theory of Cognitive Aging. New York: Elsevier Science Publishing Company, Inc.

Salthouse, T. A. (1987). Adult age differences in integrative spatial ability. Psychology and Aging, 2, $254-260$.

Salthouse, T.A. \& Prill, K.A. (1987). Inferences about age impairments in inferential reasoning. Psychology and Aging, 2, 43-51.

Salthouse, T.A. \& Somberg, B.L. (1982). Skilled performance: Effects of adult age and experience in elementary processes. Journal of Experimental Psychology; General, 111, 176-207.

Sharps, M.J. \& Gollin, E.S. (1987). Memory for object locations in young and elderly adults. Journal of Gerontology, 42, 336-341.

Simon, J. R. \& Pouraghabagher, A. R. (1978). The effect of aging on the stages of processing in a choice reaction time task. Journal of Gerontology, 33, 553-561.

Spirduso, W.W. (1980). Physical fitness, aging, and psychomotor speed: a review. Journal of Gerontology, 35, $850-865$.

Stelmach, G.E., Amrheim, P.C. Goggin, N.C. (1988). Age differences in bimanual coordination. Journal of Gerontology, 43, 18-23.

Till, R. (1985). Verbatim and inferential memory in young and elderly adults. Journal of Gerontology, 40, 316-323.

Welford, A. T. (1984). Psychomotor performance. In Annual Review of Gerontology and Geriatrics, 4, 237-273.

Wickens, C.D. \& Braune, R. \& Stokes, A. (1987). Age differences in the speed and capacity of information processing: 1. a dual task approach. Psychology and Aging, 2, 70-78.

Woollacot, Shumway-Cook, A. \& Nashner, L.M. (1986). Aging and posture control changes in sensory organization and muscular coordination. Aging and Human Development, 23, 97-115. 
Wright, R. E. (1981). Aging, divided attention, and processing capacity. Journal of Gerontology, 36, 605-614.

Zacks, R.T., Hasher, L., Doren, B., Hamm, V., \& Attig, M.S. (1987). Encoding and memory of explicit and implicit information. Journal of Gerontology, 42, 418-422. 


\section{Footnote}

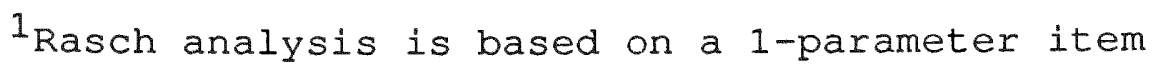
response theory (IRT). IRT is used to equate across versions of tests, such as linking 2 nd grade, 3 rd grade, and 4th grade tests of achievement together so that progress over time can be tracked. In this same way, IRT is being used to equate tasks known to have differing levels of difficulty. The advantage is that the ability measures are corrected for the difference. The closest "traditional" alternative is analysis of covariance. The difference is that the latter does not make different objects similiar; it only controls for differences in variances. Rasch is the only method available to adjust scores for the differences in difficulty (or rater severity, etc.). It is modern test theory which is rapidly replacing so called classic theory based on counts of scores known to not be equal units of whatever measured (Fisher, A., personal communication, April 19, 1991). 
Table 1

Familiarity Ratings of Package and ADL Tasks

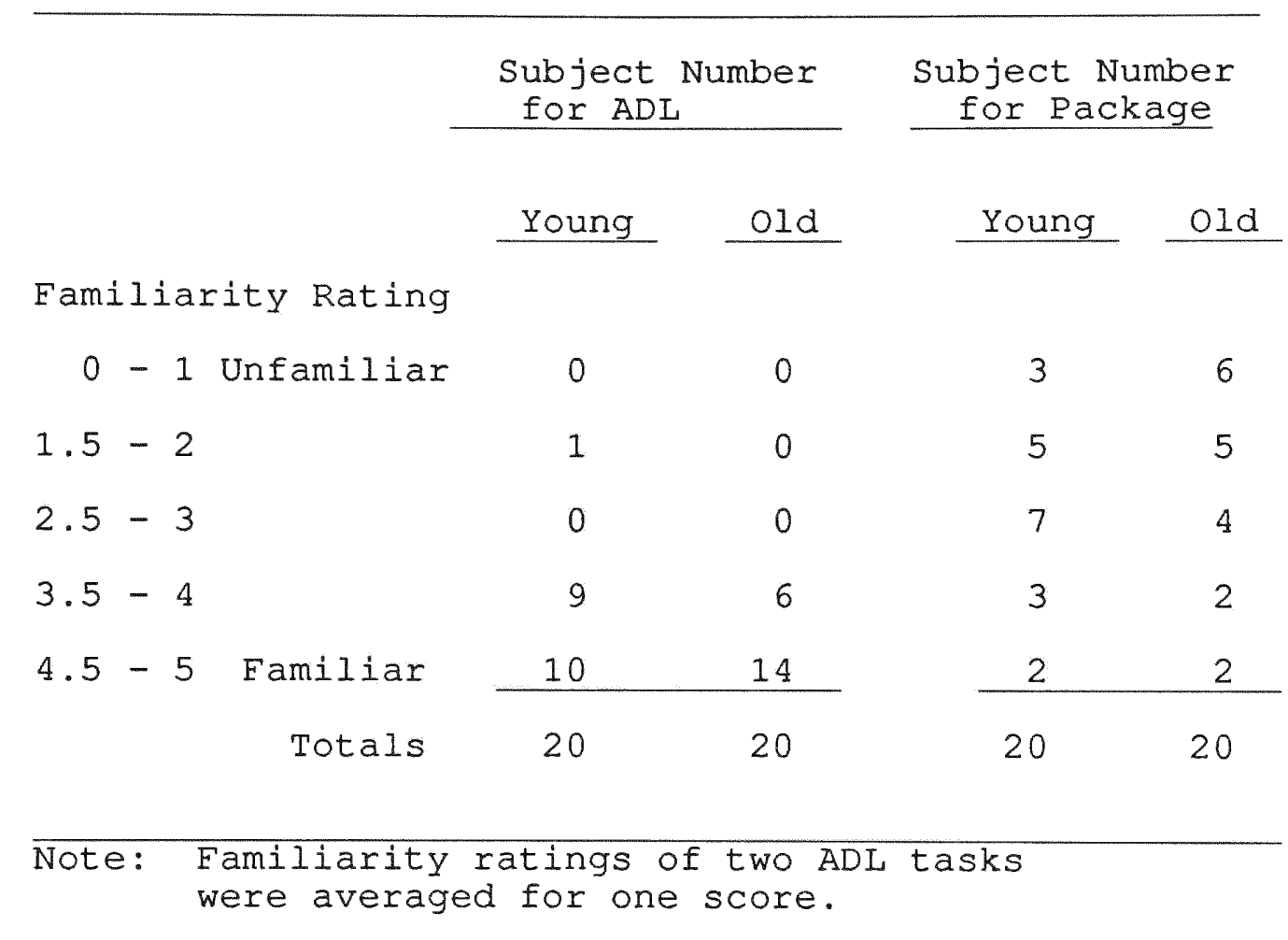


Table 2

Reported Frequency of Performing Package Task by Age

\begin{tabular}{lcc}
\hline & \multicolumn{2}{c}{ Number of Subjects } \\
\cline { 2 - 3 } & Young & old \\
\cline { 2 - 3 } Frequency & & 6 \\
Never & 11 & 5 \\
$1-2$ times per year & 3 & 2 \\
$3-4$ times per year & 2 & 3 \\
1 time per month & 1 & 2 \\
$2-3$ times per month & 0 & 1 \\
1 time per week & 1 & 1 \\
More than once per week & 20 & 20 \\
Totals & & \\
\hline
\end{tabular}


Table 3

Mean Scores for Tasks

\begin{tabular}{lrrrrr}
\hline & \multicolumn{2}{c}{ Young } & \multicolumn{2}{c}{ Old } \\
\cline { 2 - 6 } & & $\mathrm{M}$ & $\mathrm{SD}$ & $\mathrm{M}$ & $\mathrm{SD}$ \\
Actvities of Daily Living & & & & \\
$\quad \begin{array}{l}\text { Process } \\
\text { Motor }\end{array}$ & 2.05 & .64 & 1.62 & .52 \\
Package & 4.54 & .58 & 3.34 & 1.20 \\
$\quad$ Process & & & & & \\
$\quad$ Motor & 2.16 & .69 & 1.49 & .72 \\
& 5.13 & 1.17 & 3.17 & 1.67 \\
\hline
\end{tabular}


Table 4

MANOVA Table

\begin{tabular}{llll}
\hline Source & DF & $F$ & p value \\
\hline
\end{tabular}

Between Subjects

$\begin{array}{lrrr}\text { AGE } & 2,37 & 12.08 & .001 * \star \\ \text { Process } & 1,38 & 9.95 & .003 * \star \\ \text { Motor } & 1,38 & 23.73 & .001 * \star\end{array}$

Within subjects

$\begin{array}{cccc}\text { TASK } & 2,37 & 0.49 & .615 \\ \text { Process } & 1,38 & 0.01 & .939 \\ \text { Motor } & 1,38 & 0.98 & .330 \\ \text { AGE by TASK } & 2,37 & 2.05 & .143 \\ \text { Process } & 1,38 & 1.20 & .281 \\ \text { Motor } & 1,38 & 3.44 & .072 \\ \star \star \mathrm{p}<.01 & & & \end{array}$


Table 5

Ranking of Tasks According to Difficulty with Many-Faceted Rasch Logit Measures for Motor and Process

\section{Measure Logit}

Task - Ranked in order of easiest to hardest

MOTOR

Plant

Grilled cheese

Egg, toast, \& coffee

Vaccum

Change bed

Toss salad

Tuna salad sandwich

Fruit salad

Package

0.64

0.56

0.25

0.22

0.10

$-0.10$

$-0.35$

$-0.61$

$-0.70$

PROCESS

Change bed

0.69

Egg, toast, \& coffee

0.42

0.33

Grilled cheese

0.25

Fruit salad

Plant

Tuna salad

$-0.23$

$-0.24$

Toss salad

Package

$-0.27$

$-0.27$

$-0.68$ 


\section{Figure Caption}

Figure 1. Scatterplot of process measures in ADL and package tasks by age. 


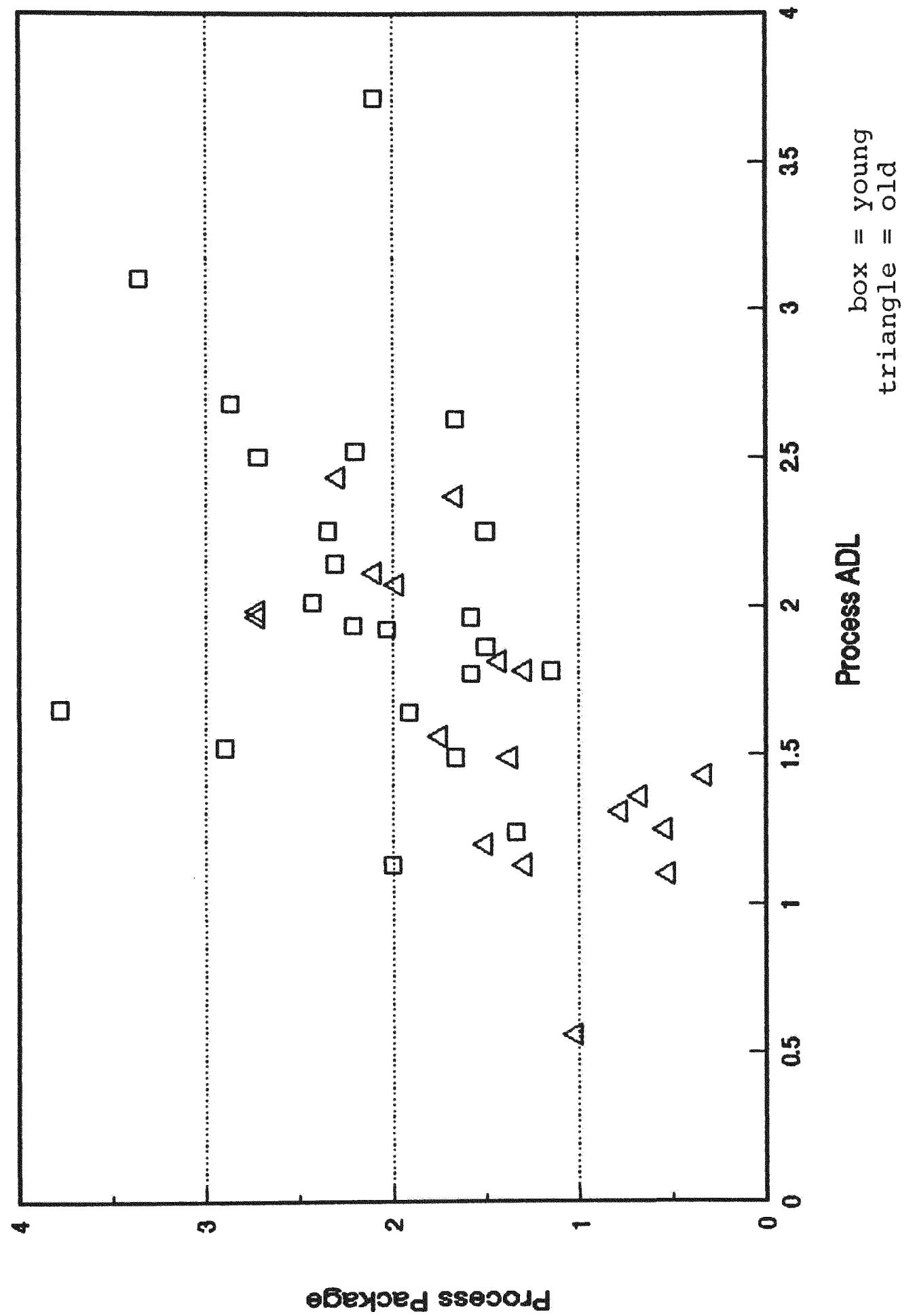




\section{Figure Caption}

Figure 2. Scatterplot of motor measures in ADL and package tasks by age. 


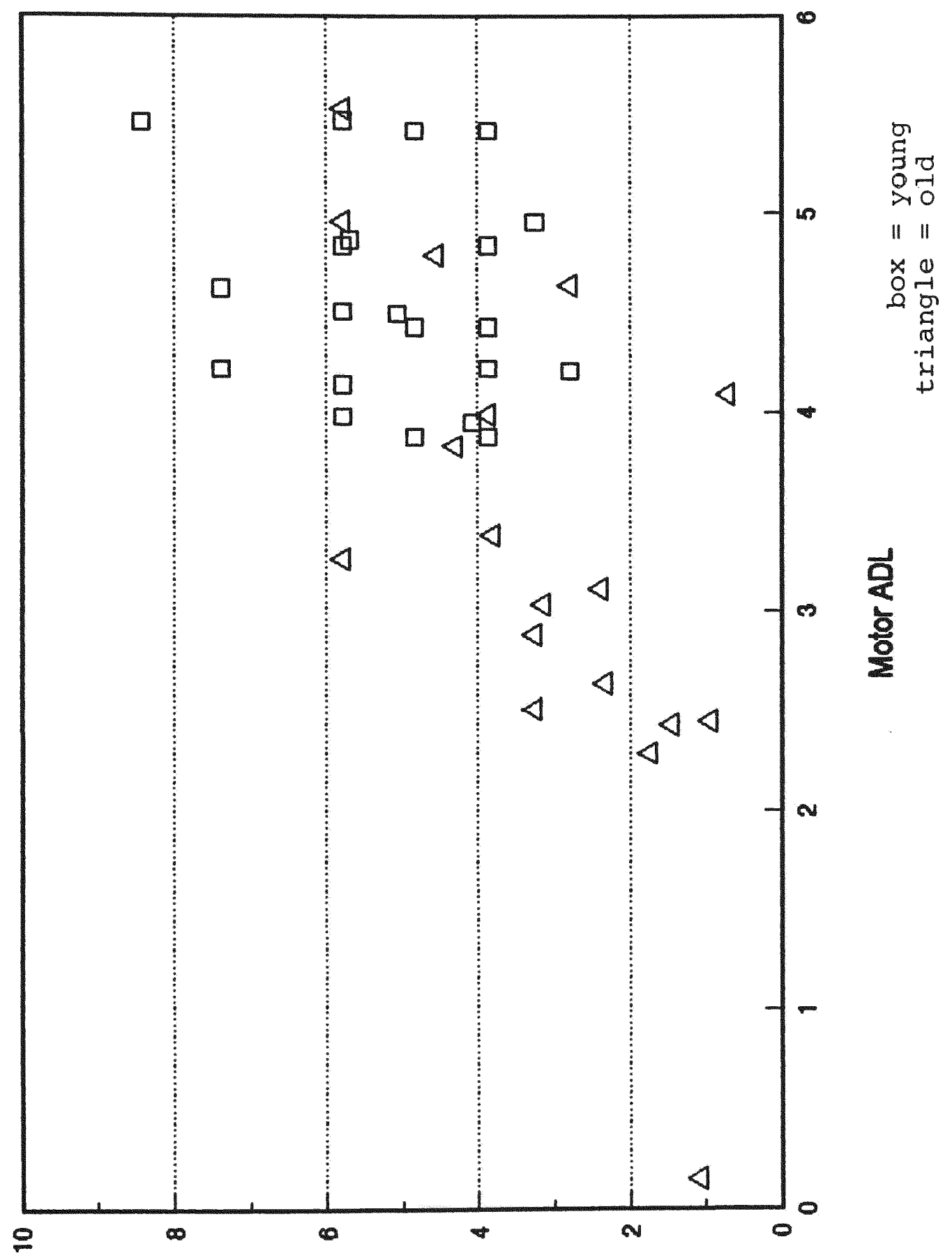

ebeyoed solow 
Appendix A 


\section{AMPS SCORE SHEET}

\begin{tabular}{|c|c|c|c|}
\hline COMPETENT & OUESTIONABLE & INEFFECTIVE & DEFICIT \\
\hline $\begin{array}{l}\text { Competent performance that } \\
\text { supports the action } \\
\text { progression and yields good } \\
\text { outcomes: Examiner } \\
\text { observes no evidence of a } \\
\text { deficit }\end{array}$ & $\begin{array}{l}\text { Questionable performance } \\
\text { that places the action } \\
\text { progression at risk and vields } \\
\text { uncertain outcomes: } \\
\text { Examiner questions the } \\
\text { presence of a deficit }\end{array}$ & $\begin{array}{l}\text { Ineffective performance that } \\
\text { interferes with the action } \\
\text { progression and yields } \\
\text { undesirable outcomes: } \\
\text { Examiner observes a mild to } \\
\text { moderate deficit }\end{array}$ & $\begin{array}{l}\text { Deficit performance that } \\
\text { impedes the action } \\
\text { progression and yields } \\
\text { unacceptable outcomes: } \\
\text { Examiner observes a severe } \\
\text { deficit (risk of damage, } \\
\text { danger, or task breakdown) }\end{array}$ \\
\hline
\end{tabular}

\section{POSTURE}

\begin{tabular}{llllll} 
Stabilizes & 4 & 3 & 2 & 1 \\
\hline Aligns & 4 & 3 & 2 & 1 \\
\hline Positions & 4 & 3 & 2 & 1 \\
\hline
\end{tabular}

\section{MOBLITY}

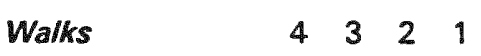

Reaches $4 \quad \begin{array}{llll} & 3 & 2\end{array}$

$\begin{array}{lllll}\text { Bends } & 4 & 3 & 2 & 1\end{array}$

\section{COORDINATION}

\section{$\begin{array}{lllll}\text { Coordinates } & 4 & 3 & 2 & 1\end{array}$}

$\begin{array}{lllll}\text { Manipulates } & 4 & 3 & 2 & 1\end{array}$

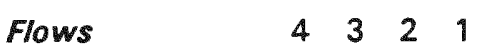

\section{STRENGTH AND EFFORT}

$\begin{array}{lllll}\text { Moves } & 4 & 3 & 2 & 1\end{array}$

\begin{tabular}{lllll}
\hline Transports & 4 & 3 & 2 & 1
\end{tabular}

$\begin{array}{lllll}\text { Lifts } & 4 & 3 & 2 & 1\end{array}$

$\begin{array}{lllll}\text { Calibrates } & 4 & 3 & 2 & 1\end{array}$

$\begin{array}{lllll}\text { Grips } & 4 & 3 & 2 & 1\end{array}$




\section{Endures}

$\begin{array}{llll}4 & 3 & 2 & 1\end{array}$

$\begin{array}{lllll}\text { Attends } & 4 & 3 & 2 & 1\end{array}$

\section{USING KNOWLEDGE}

\begin{tabular}{lllll} 
Chooses & 4 & 3 & 2 & 1 \\
\hline Uses & 4 & 3 & 2 & 1 \\
\hline Handles & 4 & 3 & 2 & 1 \\
\hline Heods & 4 & 3 & 2 & 1 \\
\hline Inquires & 4 & 3 & 2 & 1 \\
\hline Notices & 4 & 3 & 2 & 1
\end{tabular}

TEMPORAL ORGANIZATION

Initiates

$\begin{array}{llll}4 & 3 & 2 & 1\end{array}$

Continues

$\begin{array}{llll}4 & 3 & 2 & 1\end{array}$

Sequences

$\begin{array}{llll}4 & 3 & 2 & 1\end{array}$

Paces

$\begin{array}{llll}4 & 3 & 2 & 1\end{array}$

$\begin{array}{lllll}\text { Terminates } & 4 & 3 & 2 & 1\end{array}$

SPACE AND OBJECTS

Searches

$\begin{array}{llll}4 & 3 & 2 & 1\end{array}$

Gathers

$\begin{array}{llll}4 & 3 & 2 & 1\end{array}$

Organizes

$\begin{array}{llll}4 & 3 & 2 & 1\end{array}$

Restores

$\begin{array}{llll}4 & 3 & 2 & 1\end{array}$ 


\section{Accommodates $4 \quad 3 \quad 21$}

$\begin{array}{lllll}\text { Adjusts } & 4 & 3 & 2 & 1\end{array}$

Navigates

$\begin{array}{llll}4 & 3 & 2 & 1\end{array}$

Benefits

$\begin{array}{llll}4 & 3 & 2 & 1\end{array}$ 
ACCOMMODATES - modifies one's actions in anticipation of, or in response to,

circumstances/problems that might arise in the course of action, or that require attention to avoid undesirable outcomes. The main focus of this behavior is that the individual changes tho method with which he/she is performing the action sequence, or the manner in which he/she interacts with or handles tools and materials already in the workspace. Includes the ability to ask for assistance when appropriate or needed. (Note. Score asking questions related to seeking information under the process verb Inquires.)

$4=$ readily and consistently modifies actions to prevent or correct for problems

- no apparent need to accommodate suggests that problems were anticipated and prevented; that is, no problems occurred or were observed

- $\quad$ turns knife over upon realizing that the sharp side is up

- slows speed of pouring to prevent water from spilling over the top

- $\quad$ slows the speed of gait on uneven or slippery surfaces

- asks for help when it is appropriate or needed le.g., when an action is too difficult, asking "will you please help?")

- $\quad$ slides jar out of the way to avoid knocking it over while cutting a sand $w^{*} \mathrm{ch}$

3 = questionable accommodation skill, but no apparent disruption of action item or task performance, or impact on other skill items

- possible hesitation or slowness to accommodate

- examiner questions the need for, or appropriateness of, the accommodation

$2=$ ineffective accommodation skill impacts on action item or task performance, or results in inefficient use of time or energy

- delay in turning the knife over results in overall slowing of task progression

- delay in slowing the speed of watering results in water filling to the brim, and possibly a little spilling over

- failure to slow down or to hold on to an available railing, furniture, or counter top results in some unsteadiness

- delay in asking for help results in overall slowing of task progression, or asks for help that is inappropriate or not needed

- not sliding jar out of the way results in use of awkward/inefficient arm movements to cut sandwich

1 = severity of accommodation skill deficit clearly impedes action item or task performance such that the results are unacceptable, or damage or danger is imminent

- failure to turn the knife over results in tomato being smashed rather than cut, or imminent risk that the client will get cut

failure to slow speed of pouring results in marked water spillage

failure to hold on or to slow down results in the imminent risk of a fall or injury

failure or marked delay in asking for help results in imminent breakdown of action progression or in an unacceptable delay

resting a tool in a precarious position results in imminent risk of damage or danger

- failure to compensate for motor or process deficits

- examiner intervention required because severity of accommodation skill deficit results in task breakdown, or in imminent risk of damage or danger failure to move jar out of the way while cutting a sandwich results in the jar being knocked over onto the floor 


\section{Appendix B}

\section{TASK CHOICES}

1. Egg, toast, and brewed coffee

2. Fresh fruit salad

3. Tossed salad

4. Grilled cheese sandwich and beverage

5. Repotting a small houseplant

6. Vacuuming living room: heavy

7. Changing sheets on a bed 


\section{APPENDIX C}

\section{Matrix for scoring skill Items}

\begin{tabular}{|c|c|}
\hline ore & $\begin{array}{l}\text { Quality of } \\
\text { performance }\end{array}$ \\
\hline
\end{tabular}

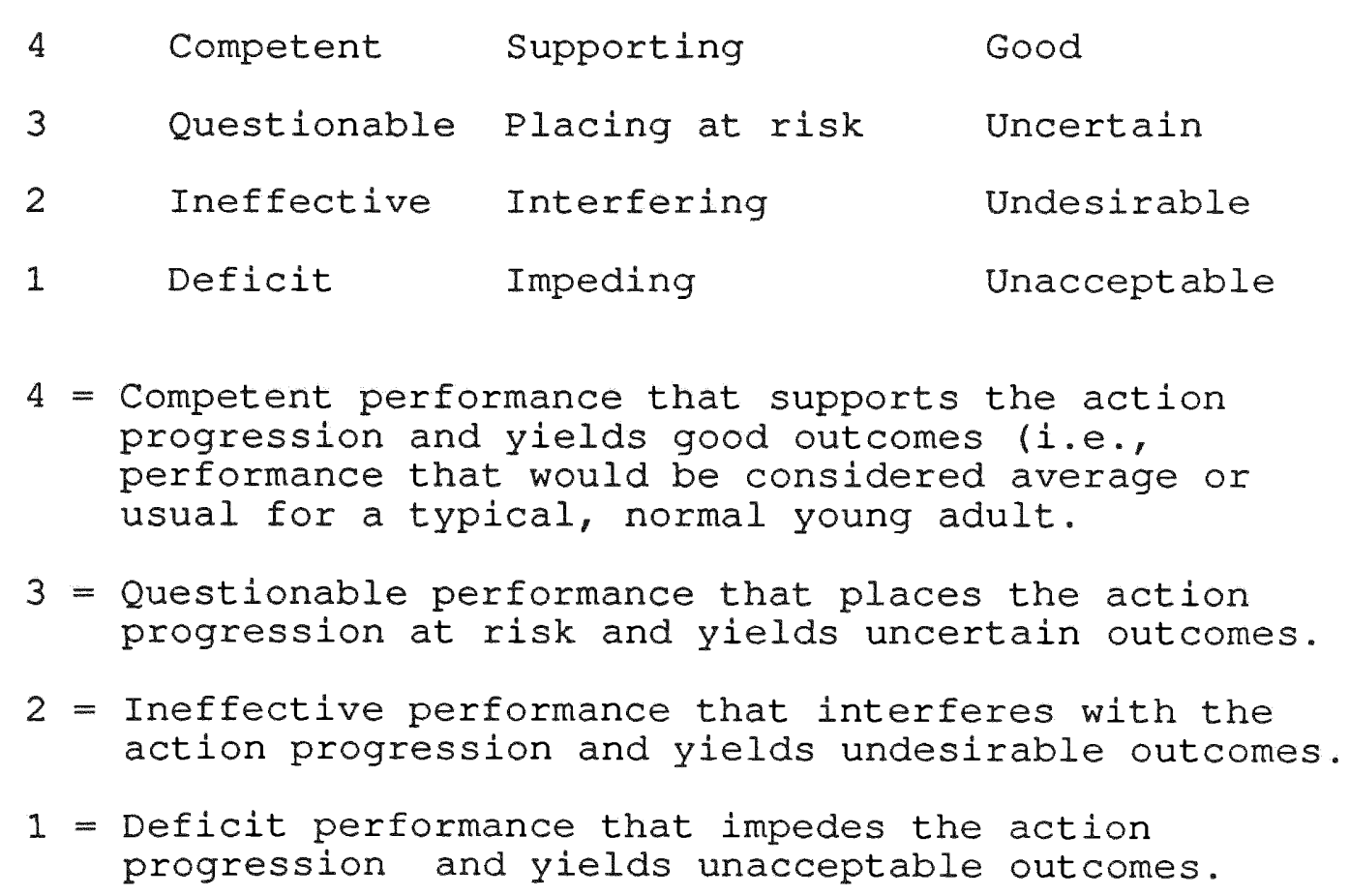


March 23, 1955

1977

1987

1986,1987

1987-present
Born, Allentown, Pennsylvania

B.S., Occupational Therapy Temple University

Philadelphia, Pennsylvania Summa Cum Laude President's Scholar

M.S., Allied Health Education/ Health Administration

Southwest Texas State University San Marcos, Texas

Scholastic Excellence Awards

Assistant Professor

Department of Occupational Therapy

Florida International University

\section{PUBLICATIONS AND PRESENTATIONS}

Dickerson, A. (1990). Evaluating productivity and profitability in occupational therapy contractual work. American Journal of Occupational Therapy, 44, $133-137$.

Dickerson, A. (1990). Developing a variable budget for occupational therapy contractual work. American Journal of Occupational Therapy, 44, 803-807.

Dickerson, A. \& Kaplan, S.H. (1991). A comparison of craft usage and academic preparation of craft modalities. American Journal of Occupational Therapy, $45,1-7$.

\section{THESIS TITLE}

Age Differences in Functional Performance: Deficits or Artifact?

Date:

Signature: 